\title{
Stormwater Management Design: Model for a Senior Undergraduate Course
}

\author{
Andrea Bradford, Ph.D., P.Eng., Assistant Professor, University of Guelph
}

Stormwater management design makes up half of a fourth year undergraduate course that also includes design of water distribution systems and wastewater and stormwater collection systems. Learning is supported by lectures with PowerPoint presentations that include many images. Early emphasis is placed on understanding the effects of urbanization, in terms of hydrology, geomorphology, water quality and stream ecology. This leads to the objectives of stormwater management and discussion of both traditional and emerging design criteria, as well as provincial guidelines and municipal standards. The students gain an appreciation of the need for a 'treatment train' approach prevention followed by lot-level, conveyance, and if necessary, end-of-pipe measures - to achieve the multiple objectives of stormwater management. Students master screeninglevel design that addresses land use, physical feasibility, climate, watershed opportunities and constraints, community factors, and the capability for various stormwater management practices (SWMPs) to meet various water quantity and quality objectives. Details and design examples for a range of SWMPs such as infiltration trenches, biofiltration swales, and extended detention wet ponds are presented, and a field trip reinforces the in-class information. The students gain design experience by means of a term project in which four person teams design the water-related infrastructure of a new subdivision. A Terms of Reference is provided at the beginning of the term. The design teams are responsible for a proposal, which initiates early project management, an oral progress report, and a final design report and presentation. Design labs provide an opportunity to introduce students to the software (EPA SWMM 5.0) but are primarily devoted to working on the design project. The design project is evaluated in terms of product and process, and both group and individual marks are assigned. Designs are evaluated prior to the final presentations enabling the instructor to provide substantive feedback before the course concludes. For the most part, the quality of work done by the students over the last several years has been exceptional. During the course, common feedback from the students includes "lack of direction" and "heavy work load." Following the course, students appreciate the understanding of the subject material and the design experience gained, which they find to be very relevant to employment opportunities. 